\title{
Implementing a Clinical Ethics Needs Assessment Survey: Results of a Pilot Study (Part 2 of 2)
}

\author{
Andrea Frolic • Sandra Andreychuk • \\ Wendy Seidlitz • Angela Djuric-Paulin • \\ Barb Flaherty $\cdot$ Barb Jennings $\cdot$ Donna Peace
}

Published online: 2 December 2012

(C) Springer Science+Business Media Dordrecht 2012

\begin{abstract}
This paper details the implementation of the Clinical Ethics Needs Assessment Survey (CENAS) through a pilot study in five units within Hamilton Health Sciences. We describe how these pilot sites were selected, how we implemented the survey, the significant results and our interpretation of the findings. The primary goal of this paper is to share our experiences using this tool, specifically the challenges we encountered conducting a staff ethics needs assessment across different units in a large teaching hospital, and the facilitators to our success. We conclude with a discussion of the limitations of this study, our plans for using the results to develop a proactive ethics education strategy, and suggestions for other organizations wishing to adapt the CENAS to assess their staff ethics needs. Our secondary goal is to advance the "quality agenda" for ethics programs by demonstrating how a tool like the CENAS can be used to design more effective educational interventions, and to support strategic planning and proactive priority-setting for ethics programs.
\end{abstract}

Keywords Ethics committees - Survey - Strategic planning · Priority setting · Interprofessional · Needs · Ethics education - Hospital - Organizational ethics · Ethical climate

\section{Introduction}

This paper details the implementation of the Clinical Ethics Needs Assessment Survey (CENAS) described in Part 1 (Frolic et al. 2012; to view the full version of

A. Frolic $(\bowtie) \cdot$ S. Andreychuk · W. Seidlitz · A. Djuric-Paulin ·

B. Flaherty $\cdot$ B. Jennings $\cdot$ D. Peace

Hamilton Health Sciences, Hamilton, ON, Canada

e-mail: frolic@hhsc.ca

\section{A. Frolic}

Professional Affairs, Hamilton Health Sciences, McMaster University Medical Center, 1F9 - 1200 Main Street West, Hamilton, ON L8N 3Z5, Canada 
the CENAS see http://www.hamiltonhealthsciences.ca/ethics) through a pilot study in five units within Hamilton Health Sciences (HHS), including the pediatric critical care unit, the neonatal intensive care unit, two adult intensive care units and an outpatient Cancer Center. We describe how these pilot sites were selected, how we implemented the survey, the significant results and our interpretation of the findings. The primary goal of this paper is to share our experiences using this tool, specifically the challenges we encountered conducting a staff ethics needs assessment across different units in a large teaching hospital, and the facilitators to our success. We conclude with a discussion of the limitations of this study, our plans for using the results to develop a proactive ethics education strategy, and suggestions for other organizations wishing to adapt the CENAS to assess their staff ethics needs. The appendices provide support materials for the implementation of the CENAS, including an invitation letter, qualitative data codebook, and an education plan for enhancing staff ethics capacity. Our secondary goal is to advance the "quality agenda" for ethics programs by demonstrating how a tool like the CENAS can be used to design more effective educational interventions, and to support strategic planning and proactive priority-setting for ethics programs.

\section{Background and Methods}

The CENAS research team opted to conduct a multi-site pilot implementation of the CENAS as this would enable the team to identify trends and themes both within and across different clinical units, to inform the development of appropriate unit-level as well as organization-level responses (such as the development of an institutional policy to address a common concern). A multi-site pilot also would help the team to identify challenges and facilitators to implementing the CENAS in different clinical contexts to assist in an effective roll-out of the survey to the broader organization in a future phase of research. This multi-site pilot study received Research Ethics Board (REB) approval from HHS' REB in October 2010.

The five sites selected to pilot the CENAS were selected for several reasons:

- Each had a local ethics resource person [either a member of the Ethics Consultation Service (ECS) or Hospital Ethics Committee (HEC)] available to answer staff questions, advocate for the project, interpret the results, and support implementation of projects inspired by the findings.

- Three of the units historically had high rates of ethics consultation utilization (one ICU, the NICU and PCCU) and two had low rates of ethics consultation utilization (the second ICU, and cancer center), providing a window into a range of staff experiences with the ethics program.

- They included all three of HHS's acute care hospital sites.

- They spanned both adult and pediatric patient populations.

- They included inpatient and outpatient units with a variety of staffing models.

The project team included representatives of each of the pilot units. This team was involved in every phase of development, from preliminary drafting of the survey tool, to validation, to writing the research protocol, to implementation of the survey, to interpretation and dissemination of results (see Table 1). 
Table 1 CENAS timeline

\begin{tabular}{ll}
\hline Phase 1 & $\begin{array}{l}\text { Develop, validate and refine CENAS tool (November 2009-April 2010) } \\
\text { Phase } 2\end{array}$ \\
$\begin{array}{c}\text { Develop research protocol for pilot study (identify pilot sites, gather research team, } \\
\text { create consent form, develop promotional materials, get permissions from sites, } \\
\text { complete Research Ethics Board approval process) (April-October 2010) }\end{array}$ \\
Phase 3 \\
Phase 4 \\
Phase 5
\end{tabular}

To understand the stragetic priorities for HHS's ethics program, the CENAS was designed to answer six questions:

(1) How do staff perceive the ethical climate within their programs?

(2) What are the primary ethical issues encountered by staff in clinical practice?

(3) What education do they want to help them address these ethical issues?

(4) Are staff aware of current ethics-related policies, guidelines and legislation within the hospital? Are additional policies or guidelines needed?

(5) What are the barriers or challenges to utilizing the hospital's ECS? ${ }^{1}$

(6) What educational strategies will be most effective to build staff capacity in the context of interprofessional care delivery?

Results of the study would be applied to develop a tailored strategy to address the needs of each site; this strategy might include an ethics education plan and/or creating supportive resources to address specific issues (including: policies, procedures or guidelines).

For ease of implementation, the CENAS was converted into an online survey. ${ }^{2}$ An email containing an invitation letter with information about the study and a link to the online survey was emailed to all targeted staff in each pilot site at the outset of recruitment (see Appendix A). ${ }^{3}$ Flyers advertising the study were posted in the five pilot areas. Staff were given reminders at regular meetings during the study period and follow-up emails were sent 2 and 4 weeks after the opening of the study; the survey was closed after 6 weeks.

The research team felt anonymity was crucial to collecting honest answers from staff. Therefore, a decision was made to collect minimal descriptive data about

\footnotetext{
${ }^{1}$ Example of a barrier might be the perception that a staff person must get "permission" from someone (like the physician) before calling for ethics consultation support, despite our open access policy. An example of a challenge might be finding time in a busy shift to make a private call to the ECS.

2 Paper copies were available for staff who were unable to complete the online survey; pre-addressed stamped envelopes enabled staff to return their anonymous surveys directly to the office of the ethics program. These surveys were entered into the online tool by the program secretary; only 10 people completed the survey on paper.

3 Different sites have different professional compositions; some include social workers, respiratory therapists, dieticians, health care aides, etc., while others primarily employ nurses/physician dyads. Each site was expected to invite interprofessional participation in the study appropriate to their staffing model.
} 
respondents as knowing the respondents' gender and profession alone would make them identifiable in some units. Only one question indicating home unit was a "forced" question; all others were optional for respondents to complete. Each participant was assigned a numerical code upon submission of their survey.

All survey results were downloaded into a Microsoft Excel spreadsheet. This enabled the generation of descriptive statistics for the quantitative questions. Responses to the quantitative questions were analyzed in three ways: (1) results for all pilot sites together; (2) results for individual pilot sites; (3) results for different profession groups, specifically nurses (the largest respondent group) versus all other health professionals. Qualitative responses to open-ended questions were also downloaded into an Excel spreadsheet; analysis of these data is described in detail below.

\section{Results}

Quantitative Results

\section{Response Rates}

The total response rate for the CENAS was $29 \%$ with 270 staff and physicians participating. The research team was hoping for an overall response rate greater than $40 \%$; however, this response rate is comparable to other ethics surveys of health professionals (see Pauly et al. 2009; Pearlman et al. 2013). Anecdotally, research team members perceived a general sense of excitement and eagerness amongst staff to participate in the study across all units. However, the response rates varied widely based on profession group and unit (see Table 2). In general, managers had the highest response rates across units, followed by nurses, others and physicians. As well, pediatric units had higher response rates than adult units. Specific facilitators of the high response rates in some units likely included: visible leadership support for the survey, encouragement of staff to make it a priority, and previous exposure to the ethics program through frequent ethics consultations and/or educational sessions prior to the study. Informally staff reported the following barriers to survey completion: competition for computers and poor access to private work spaces to complete the survey; difficulty finding 15 minutes of uninterrupted time to complete the survey given heavy workloads for frontline staff; competing priorities and projects (including other surveys and projects related to an upcoming accreditation survey).

\section{Ethical Climate}

Over the past 15 years, increasing attention has been paid to the ethical climate as an important aspect of the organizational climate required to support professional practice in healthcare (see McDaniel 1998; Olson 1998). According to Olsen, "Ethical climate consists of perceptions of organizational practices and conditions that facilitate the discussion and resolution of difficult patient care issues.... [It] 
Table 2 Survey response rates

\begin{tabular}{lllllll}
\hline $\begin{array}{l}\text { Response rate by } \\
\text { profession group } \\
\text { (n respondents) }\end{array}$ & $\begin{array}{l}\text { Adult } \\
\text { critical } \\
\text { care-1 }\end{array}$ & $\begin{array}{l}\text { Adult } \\
\text { cancer } \\
\text { centre }\end{array}$ & $\begin{array}{l}\text { Adult } \\
\text { critical } \\
\text { care-2 }\end{array}$ & NICU & PICU & All sites \\
\hline Manager & $50 \%(1)$ & $50 \%(1)$ & $100 \%(2)$ & $\mathrm{n} / \mathrm{a}$ & $100 \%(2)$ & $75 \%(6)$ \\
Business clerk & $0 \%(0)$ & $\mathrm{n} / \mathrm{a}$ & $20 \%(2)$ & $25 \%(5)$ & $17 \%(1)$ & $16 \%(8)$ \\
Health care aides & $\mathrm{n} / \mathrm{a}$ & $\mathrm{n} / \mathrm{a}$ & $\mathrm{n} / \mathrm{a}$ & $6 \%(1)$ & $\mathrm{n} / \mathrm{a}$ & $6 \%(1)$ \\
Medicine & $33 \%(4)$ & $21 \%(11)$ & $25 \%(1)$ & $14 \%(2)$ & $17 \%(1)$ & $22 \%(19)$ \\
Nursing & $14 \%(34)$ & $41 \%(16)$ & $24 \%(18)$ & $43 \%(83)$ & $94 \%(50)$ & $33 \%(201)$ \\
Other & $0 \%(0)$ & $\mathrm{n} / \mathrm{a}$ & $\mathrm{n} / \mathrm{a}$ & $100 \%(3)$ & $100 \%(2)$ & $63 \%(5)$ \\
Professional practice & $11 \%(7)$ & $\mathrm{n} / \mathrm{a}$ & $9 \%(3)$ & $23 \%(5)$ & $48 \%(13)$ & $19 \%(28)$ \\
Total & $14 \%(46)$ & $30 \%(28)$ & $21 \%(26)$ & $37 \%(100)$ & $73 \%(70)$ & $29 \%(270)$ \\
\hline
\end{tabular}

The response rate was calculated based on a ratio of completed responses compared to the total staff in each category who received the survey. The response rate was more difficult to calculate than the research team originally anticipated for three reasons. First, not all units had the same complement of professionals, nor did they categorize professionals in the same way (i.e., some units categorized Respiratory Therapists as "other" while others designated them as "professional practice"). Second, our original attempt to calculate response rates included all staff on the payroll of the unit (including those on leave, on vacation, etc.), resulting in an underestimation of the true response rate. Third, some units share staff members; because the survey is anonymous it is impossible to know which unit particular respondents chose to identify with, negatively impacting the response rate for the other unit. Note N/A indicates that either a profession group was not included in the survey for logistical reasons or is not part of the staffing model of within a particular site

emerges from interaction with others in the workplace, is influenced by leadership and, in turn, influences the behaviors and beliefs of employees. Ethical climate provides the context for ethical decision-making..." (Olson 2002). In other words, the ethical climate of an organization is the shared set of understandings about what is correct ethical behavior and how ethical issues are typically handled (Silverman 2000). Hart found in her study of nursing turnover in the USA that the ethical climate was a significant factor in nurses' decisions to leave their current positions and, in some cases, the nursing profession. Further, she found that ethics education and previous ethical conflict both contributed to nurses' intentions to stay (Hart 2005).

The CENAS gauges staff perceptions of the ethical climate in their units, to determine their perception of ethics in the everyday workplace and how well teams work together to integrate values into practice and address ethical concerns. Grouping positive (agree fully, agree somewhat) and negative responses (disagree somewhat, disagree fully) reveals wide variability between sites on several measures (see Table 3). The questions with consistently high positive responses ( $a$ and $b$, regarding respect and confidentiality) were also the questions with the lowest spread between sites, indicating that these features of the ethical climate appear to be consistently present across all sites. These aspects of the ethical climate are linked to recent hospital-wide educational initiatives leading up to the survey, including development of a staff code of conduct emphasizing respect, and the introduction of new privacy legislation. Those aspects of the climate that rely upon 
collaboration between staff or leadership support tended to receive a lower rating (c, $\mathrm{g}, \mathrm{h}$ ). The unit with the most positive ethical climate overall-the Cancer Center, with over $71 \%$ of respondents responding positively to all questions except (i) also has the smallest interprofessional teams; most work in nurse-physician dyads. Adult critical care units reported the poorest ethical climates overall, with both units responding significantly below the mean on all questions but a and b. The two children's hospital units (NICU and PICU) trended closer to the mean and were similar to each other (within $10 \%$ ) in their positive responses to all but three of the questions. The most significant differences between units (over $30 \%$ spread) related to the categories of decision-making (c), leadership practices (d) and living the values of the organization (j). In all units, a majority of respondents felt that ethics education was inadequate.

The variation between sites on measures of ethical climate reveals the importance of conducting unit-specific analysis as averages mask significant differences. As a team we realized that ethical climate is extremely local; understanding the results requires knowledge of the particular cultures and histories of each site. Subjectively, it is difficult to verify why climates vary; healthcare is always changing and the variables affecting staff perceptions of relationships and teamwork are challenging to parse. We speculate that multiple factors account for the wide range of responses regarding the ethical climate, including:

- Different philosophies of patient care between sites: Pediatric sites tend to have a more overtly family-centred approach requiring high-levels of team collaboration in the coordination of care.

- Different structural pressures: Both adult ICUs were anticipating amalgamation with another unit during the survey period, a move that significantly impacted staff morale.

- Different leadership styles and leadership engagement with the ethics program.

- Different staffing models and schedules: Some units have physicians rotating every few days, others every few weeks, while others assign patients a primary physician. The sites also have different complements of health professionals working as part of the team.

- Different levels of integration of ethics services: Some units had more exposure to ethics consultation and ethics education than others.

Validation of the factors impacting local ethical climates could be sought by conducting focus groups with a cross-section of the interprofessional team within each unit, however, this was beyond the scope of our pilot study.

\section{Frequency of Ethical Issues}

Across all sites, most respondents indicated that they encountered ethical issues in their work weekly or monthly, with a significant minority (ranging from $9 \%$ in the NICU to $23 \%$ in the two adult ICUs) indicating that they experienced ethical issues on a daily basis (see Fig. 1). In the CENAS, "ethical issue" was used synonymously with "ethical dilemma" or "ethical conflict." These results were encouraging to the research team, as they demonstrate that staff are able to recognize ethical issues 


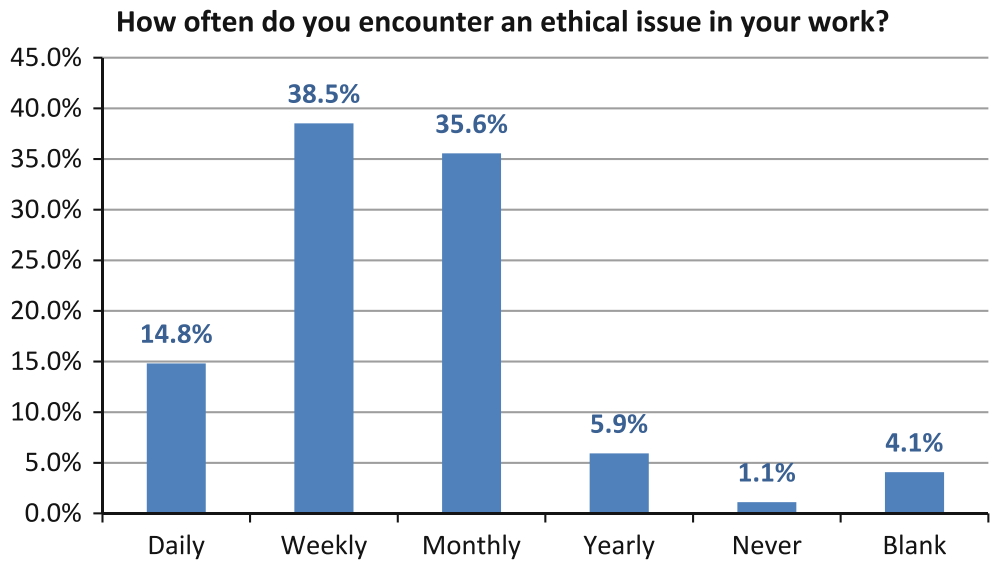

Fig. 1 Frequency of ethical issues

when they arise, and perceive them as relatively "normal" aspects of complex care delivery. This ability to recognize and normalize ethical issues is foundational to effectively addressing issues through interventions such as education, consultation or policy development.

\section{Awareness of Ethics-Related Policies and Resources}

In our analysis, we elected to group the "Not Aware" and "Somewhat Aware" responses, as the ideal response would be "Very Aware," indicating no need for additional information or education. All units were most familiar with policies that either had mandatory education (i.e., staff code of conduct) or frequent application in daily clinical practice (i.e., consent and confidentiality). Units reported less familiarity with policies that were newer or that apply to a limited range of clinical circumstances (i.e., organ donation). Staff also reported less familiarity with the legislation that informs their daily practices (i.e., consent and privacy).

Overall, awareness of all ethics resources was low, as fewer than $50 \%$ of respondents were "very aware" of the Clinical Ethics Committee, the Ethicist and the ECS, the three most long-standing and visible ethics resources in the organization. Even lower average rates of awareness were reported across all sites for more recent resources, including the ethics website $(10.0 \%)$ and monthly Ethics Grand Rounds $(8.9 \%)$. When asked what barriers or challenges prevented staff from utilizing ethics consultation services, respondents indicated that access was the most frequent challenge, including: not knowing how to make a consult request, assuming that only a physician can request ethics consultation, and the lack of a 24 hour on-call service.

\section{Learning Needs and Preferences}

Despite a lack of familiarity with ethics resources, staff indicated high rates of receptivity to ethics education. Over $80 \%$ of respondents across all units indicated 


\section{How important do you consider ethics education to support patient care} in your programs?

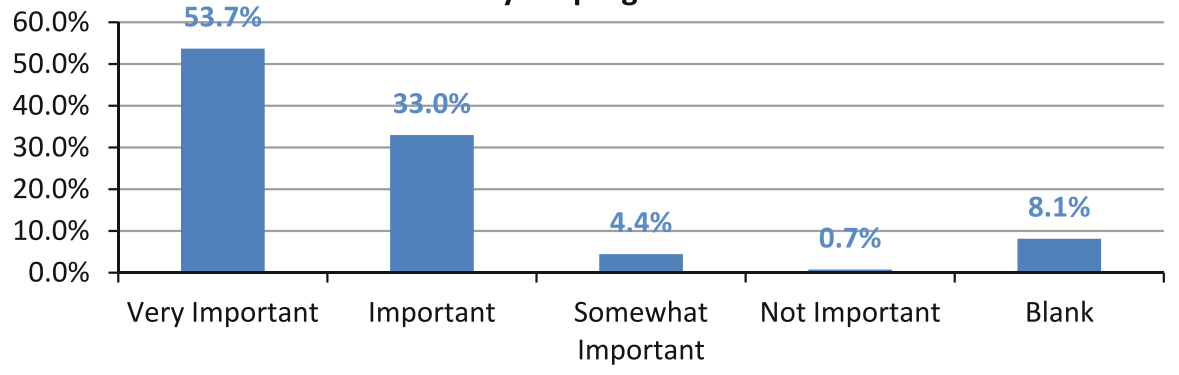

Fig. 2 Importance of ethics education

that ethics education was either "very important" or "important" in supporting patient care (Fig. 2). All units reported similar preferences for learning modalities, favoring interactive formats like facilitated informal discussions, interdisciplinary team rounds, and workshops or retreats. Least preferred amongst respondents were independent learning methods such as self-study guides, web-based learning or bulletin boards. These preferences were reinforced in the qualitative responses, which indicated a strong desire across sites to strengthen interprofessional communication and collaboration in dealing with ethical issues.

In question 10 of the survey, respondents were asked to identify from a list of ethics-related topics their personal learning needs. Of the 27 topics listed, 20 were rated as either "somewhat needed" or "really needed" by an average of $60 \%$ or more of respondents overall. This confirms a strong appetite for ethics education. Interestingly, the topics of greatest interest are not "typical" ethical issues like futility and consent, but involve everyday ethics like decision-making and teamwork. In general, the most needed topics (with $>70 \%$ of respondents indicating a need for education) clustered around four themes: effective communication (with patients/families and within the interprofessional team); decisionmaking (including developing clear plans of care and allocating resources); end-oflife care (including withdrawal of treatment and pain control); and integrating personal and professional ethics into practice (including respecting diversity) (Table 4).

\section{Qualitative Results}

We elected to invite respondents to provide qualitative responses for several reasons: (1) to help us validate the CENAS tool by enabling participants to indicate gaps in the topics queried; (2) to give participants the opportunity to share their stories; (3) to enable the research team to gauge which issues seem most pressing to respondents, to support priority setting for future projects and education. A total of 10 open-ended questions were embedded into the CENAS soliciting such information as: suggestions for policy development or other topics for education; 
Table 3 Ethical climate results

\begin{tabular}{lll}
\hline Exploring ethical climate & $\begin{array}{l}\text { Agree fully/ } \\
\text { somewhat mean } \\
\text { (range of means) }\end{array}$ & $\begin{array}{l}\text { Disagree fully/ } \\
\text { somewhat mean } \\
\text { (range of means) }\end{array}$ \\
\hline a. I feel RESPECTED by other staff members & $86.3 \%$ & $7.0 \%$ \\
& $(84.3-92.8 \%)$ & $(0-10.0 \%)$ \\
b. I feel staff members respect the CONFIDENTIALITY of & $83.4 \%$ & $11.1 \%$ \\
patients and colleagues & $(80.0-89.3 \%)$ & $(7.1-13.0 \%)$ \\
c. I feel decisions involving ETHICAL DILEMMAS are made & $64.1 \%$ & $28.9 \%$ \\
in a fair, consistent, and respectful way & $(50.0-89.3 \%)$ & $(3.6-43.5 \%)$ \\
d. I feel the practices of the LEADERSHIP TEAM within my & $72.6 \%$ & $21.8 \%$ \\
program are fair, consistent, and respectful & $(56.5-89.3 \%)$ & $(7.1-34.8 \%)$ \\
e. I feel encouraged to express my ETHICAL CONCERNS & $71.9 \%$ & $21.8 \%$ \\
& $(57.7-89.3 \%)$ & $(7.1-27.1 \%)$ \\
f. I know whom to contact about my ethical concerns when I & $68.1 \%$ & $24.9 \%$ \\
need support & $(53.8-75.0 \%)$ & $(18.0-37.0 \%)$ \\
g. I feel staff work collaboratively to address ethical concerns & $65.9 \%$ & $26.7 \%$ \\
& $(54.3-82.1 \%)$ & $(14.3-37.0 \%)$ \\
h. I feel the leadership team promotes access to ethics resources & $61.1 \%$ & $31.8 \%$ \\
& $(45.6-71.4 \%)$ & $(25.0-45.7 \%)$ \\
i. I feel staff are provided with adequate ethics education & $44.1 \%$ & $48.9 \%$ \\
j. I feel the values of HHS are reflected in everyday practices & $(34.8-50.0 \%)$ & $(45.0-57.7 \%)$ \\
and decisions in my program & $(53.9-92.9 \%)$ & $20.0 \%$ \\
\hline
\end{tabular}

how ethical issues are typically addressed in their units; barriers to utilizing the ECS; and personal stories about ethical dilemmas encountered in practice. About fifty percent of the 270 respondents completed one or more qualitative question, generating a total of 1,674 qualitative comments. The research team reviewed all the qualitative data to develop themes relevant to each question, and then grouped themes into related categories. To limit researcher bias, the researchers trained 3 students to analyze the data using the codebook created (see Appendix B). Each student independently coded the qualitative responses and subsequently engaged in dialogue to reach a consensus on the categorization of each response.

The qualitative responses indicate a strong desire for more support and education surrounding end-of-life issues across all sites. Respondents frequently requested guidelines for: appropriate resuscitation orders; understanding and honoring patients' previously expressed wishes; conducting timely end-of-life discussions/ decisions; transitioning patients to palliative care; providing pain control and comfort care; avoiding futile care and ensuring quality of life. The second and third most frequently cited needs related to communication and teamwork, as well as conflict management. The only novel topics that surfaced in the qualitative questions pertained to moral distress, professional practice issues and legal concerns. 
Table 4 Most needed topics for education

\begin{tabular}{ll}
\hline Most needed topics for ethics education & $\begin{array}{l}\text { Really and } \\
\text { somewhat } \\
\text { needed (\%) }\end{array}$ \\
\hline Strategies for working with challenging patient/family situations & 84.40 \\
Ethical decision-making tools & 82.60 \\
Ethical issues related to pain, symptom control and sedation & 75.90 \\
Personal ethics and reflective practice & 75.20 \\
Conflict resolution & 75.10 \\
Communication with families & 74.80 \\
Roles in decision making (professional, family and patient) & 74.80 \\
Establishing clear goals and plans for care & 74.50 \\
Quality of life & 74.40 \\
Breaking bad news/truth telling & 73.30 \\
Resource allocation and priority setting & 73.00 \\
Religious and cultural diversity & 73.00 \\
Providing quality end of life care & 72.60 \\
Withholding/withdrawing life-sustaining treatments & 72.60 \\
Interprofessional team communication & 72.50 \\
Adverse medical events (reporting, disclosure, and follow-up) & 72.20 \\
Shifting to palliative care & 71.90 \\
\hline
\end{tabular}

When asked how ethical issues are typically addressed within their units, respondents indicated the two preferred methods are family and/or team meetings or avoiding/ignoring the issue. The major challenges to addressing ethical issues are: team cohesiveness; communication issues; lack of ownership; staff changeover; conflict management; inadequate clinical understanding of situation by patient/ family; and balancing personal and professional values. These results are consistent with the quantitative responses, corroborating the top priority topics for ethics education.

Most of the examples of ethical issues shared by respondents involved end of life scenarios. This is unsurprising given the patient populations served by the units surveyed, which tend to have high mortality rates. Given the high response rate for the qualitative questions, respondents seemed to welcome the opportunity to share their feelings, stories and concerns frankly. Their stories provided helpful illustrations of how particular gaps in knowledge or skills play out in the actual provision of patient care (see Appendix B for examples). The poignance of many of these stories also indicates how distressing ethical dilemmas can be for staff. These stories helped to corroborate the quantitative results regarding staff need for conflict management and communication skills, and guidelines to deliver quality end of life care. The tenor of the qualitative responses indicate that moral distress is a common experience in these units; therefore, it may be useful to expand the CENAS to add a specific section querying staff experiences of moral distress. 


\section{Reflections and Limitations}

Overall, our implementation of the CENAS yielded helpful information for setting priorities for our ethics program. There was significant agreement across units regarding the high frequency of ethical issues, the scant awareness of existing ethics resources, and the strong desire for ethics education on a wide variety of topics related to end of life care, communication and teamwork. In addition, most respondents across units indicated similar preferences for interactive team learning methods. These data point to an opportunity to develop standardized educational modules and resources that can be delivered across multiple units, allowing for greater efficiency in allocating the limited resources of the ethics program.

Across sites, the greatest variability was observed in respondents' assessment of the ethical climate, indicating that this measure is strongly influenced by local leadership, history, context and relationships. This finding highlights the importance of constructing multi-site surveys so that individual unit data can be extracted; otherwise leaders can be mislead by organization-wide averages that are skewed by outlier units. Comparative analysis can identify high-performing units; learning how they function can support change in units with poorer ethical climates.

There are three primary limitations of our pilot study of the CENAS. First, the variable response rates across units make organizational averages less meaningful, and results may not accurately represent the views and needs of most staff in the low-response units. Second, four of the five units surveyed deliver critical care. Although the Cancer Centre results were fairly similar, the needs and experiences captured by this pilot project may not be generalizable to non critical-care units. Third, response rates varied between profession groups and not all staff in all units were included (i.e., healthcare aides). Minimal demographic data were collected from participants in order to preserve their anonymity, so descriptive statistics of respondents were not reported. We wondered whether the fact that $74 \%$ of all respondents were nurses might be masking important differences between profession groups. There were insufficient numbers to run an analysis for each profession; however, the research team opted to query whether there were significant differences between nurses and all others in relation to two themes: their assessment of the ethical climate, and the frequency with which they encountered ethical issues. The results indicated that there were not significant differences between nurses and other health professionals in their responses to these questions.

The results of the CENAS have been disseminated to in a staged fashion to various stakeholders across HHS. Aggregate results were disseminated within the ethics program (i.e., to the HEC and ECS), to the Executive Team, as well as at grand rounds. Unit-specific data was shared with local leadership teams, including: physician chiefs, educators, managers and directors. Our presentations have raised three major concerns. First, the frequency that staff report encountering ethical issues. The research team has consistently framed this finding positively as it demonstrates staff are engaging in reflective practice and identifying issues; it would be much more worrying if staff in these complex patient care settings reported encountering ethical issues infrequently. The second concern was the low response rates in some units. However, when leaders were asked to reflect on their 
own perceptions of their units and whether they are surprised by any of the results, they indicated that the results are consistent with their own experiences and are likely representative. The third concern was the variability in local ethical climates across the hospital. Reflection on the specific contexts of each unit, and the challenges facing them at the time of the study, has helped to make sense of these results.

Using the results of the CENAS, the ethics program has created educational presentations on six topics frequently cited by staff across all units: (1) Professional Ethics and Reflective Practice; (2) Integrity and Moral Distress; (3) End of Life Communication; (4) Ethics of Symptom Management at End of Life; (5) Developing Appropriate Goals and Plans of Care; (6) Strategies for Dealing with Challenging Patients and Families. Given the need for capacity-building in areas such as conflict management, teamwork and communication, the ethics program is planning to collaborate with related services such as organizational development to develop and deliver some educational sessions.

Following our presentation of results to each leadership team, the units have begun to develop specific educational plans to address their particular needs, using methods best suited to their teams. Results from each unit can be used to tailor plans that allow for meaningful sequencing of topics, from foundational to more complex issues. Three units are developing working groups to design and implement monthly or bimonthly ethics sessions, alternating informal case discussions with formal education sessions to be delivered by the Ethicist or members of the ECS. The goal of these educational initiatives is not only to impart knowledge, but also to enhance the culture of each unit by integrating tools like ethics frameworks and end of life communication guides into everyday practice. An example of one educational plan developed for the NICU is outlined in Appendix C.

\section{Future Directions and Lessons Learned}

The importance of continuing education in ethics is widely recognized by health professional colleges. Assessing the ethics needs and concerns of staff is an important first step in developing a strategic approach to addressing gaps in ethics knowledge and enhancing the ethics climate. Overall, the CENAS enabled us to meet our objectives by identifying the primary ethical issues encountered in the five pilot units, and staff learning preferences to address these issues. The significant overlap between qualitative and quantitative results enhanced our confidence that the CENAS is a comprehensive tool for assessing the ethics needs of healthcare professionals. Over $90 \%$ of respondents answered all questions; this low rate of abandonment indicates that participants find the survey engaging and relevant. When results were reviewed by leaders in the surveyed units, they confirmed that the results reflect their own experiences and perceptions, bolstering the face validity and reliability of the tool.

Based on our experience, we offer the following recommendations to ethics programs wishing to implement the CENAS or any similar ethics needs assessment tool: 
- Selecting sites: Pilot your needs assessment tool in selected units that represent a cross-section of your organization's patient populations. This helps you to understand local differences, while also identifying trends that are organizationwide. This allows both appropriate tailoring and efficient development of generalizable educational interventions.

- Enhancing response rates: Clarify targeted staff in advance (and the rationale for such targeting) so the response rate can easily be calculated. Engage the leadership team in each unit to visibly support the survey (i.e., by encouraging staff to cover each other's patients and by freeing up computers to complete the survey). Tailor advertising strategies to the structure and culture of each unit. Ensure a local ethics resource person is available to answer participants' questions about the project and how the results will be used. Time your survey so that it is not competing with other initiatives.

- Survey format: Make both on-line and paper versions of the survey available to staff; while the paper version requires administrative assistance to enter the data into the online survey, it can help to increase response rates in units where access to computers is challenging.

- Survey length: The high rate of completion of all survey questions indicates that the length of the CENAS is not prohibitive. However, units without the resources to do qualitative data analysis could administer the quantitative questions only and still get meaningful results. ${ }^{4}$ Another option to shorten the survey would be to adopt a modular approach, focusing only on those questions most relevant to your particular goals (for example, leaving out the section on ethical climate).

- Additional questions: If capacity allows, it may be fruitful to expand the CENAS to assess staff needs and experiences regarding moral distress. Validation of the factors impacting local ethical climates could be sought by conducting focus groups with a cross-section of the interprofessional team within each site.

- Communicating results: In our experience, it is important to share unit specific results with local leaders before they are disseminated to all staff. Framing negative results as positive indicators of staff honesty, awareness and engagement helps to avoid defensive reactions. Where response rates are lower than expected, ask leaders to reflect on whether the results match their own perceptions and experiences. Create local working groups to direct the delivery of education; this develops local champions for ethics, and ensures that education is tailored to maximize effect.

In summary, the CENAS has proven to be a valuable tool to identify common ethical issues encountered by staff and the educational priorities of participating units. Implementing the CENAS has helped to raise the profile of the ethics program and made staff more aware of ethics services and how to access them. As our ethics

\footnotetext{
4 The qualitative questions that yielded the most significant insights for us were question 12 (What are the three ethical dilemmas/conflicts/issues that you encounter most frequently in your practice?) and question 14 (What are the barriers or challenges to addressing issues?). These questions are particularly helpful in prioritizing education topics and identifying strategies to empower staff to resolve difficult ethical issues.
} 
program embarks on its strategic planning process, these results will shape our allocation of staff time, our tactical approaches to addressing issues, and our sequencing of interventions to address the most pressing ethical concerns and enhance the ethical climate of the hospital. These results will enable our ethics program to become more proactive in addressing the root causes of ethical dilemmas, rather than reacting to issues in an ad hoc fashion. Developing common tools/guidelines and facilitating collaboration between units to address similar concerns will bolster the efficiency of our educational endeavors. These baseline data will enable our ethics program to measure the effectiveness of our interventions over time through repeat surveys. We hope our study will encourage other ethics programs to share their priority-setting strategies and methods, to enhance the quality of ethics services and maximize their potential impact within a context of resource scarcity.

Acknowledgments Thank you to Sylvie Labelle-Stimac for her contributions to the implementation of this project, and to the leaders and staff in each of the pilot sites at Hamilton Health Sciences for their support of this study and for the stories they shared to help us understand the moral dimensions of frontline care.

\section{Appendix A: Invitation to Participate in the CENAS}

\section{Dear Survey Participant:}

Ethics is the systematic examination of facts, beliefs, standards and values in determining the rightness or wrongness of decisions and actions. Ethical decisionmaking involves disciplined reflection and reasoned deliberation on how to make decisions about what should be done in a particular situation.

As health care professionals, we are continuously challenged with difficult ethical scenarios in our daily practice. Although there is general awareness that ethics education is crucial to support patient care and quality work environments, after graduation many health care professionals don't have access to relevant ethics education. In addition, there is a lack of evidence to help define what ethics education is most helpful. To address this gap, our research team developed a survey to determine the ethics education needs of staff and physicians in select pilot sites.

The primary goal of this REB-approved research is to improve the ethical climate and ethics knowledge of staff and physicians within targeted programs. This will be accomplished through three objectives: (1) to understand staff and physician needs and perspectives related to ethics within their programs; (2) to use this information as a basis to develop a strategy to meet their needs; (3) to validate this survey instrument. This survey is being piloted in five different programs. It queries a number of topics including: perceptions of the ethical climate within the programs; awareness of ethics-related policies; awareness of ethics resources; and finally, staff and physician experiences of ethical issues. The anonymous aggregate data will be shared with key stakeholders and leaders in each of the pilot programs, to support the development of a strategy to meet staff and physician needs. 
The research team is requesting your response to the attached questionnaire. We anticipate that this will take 15-20 minutes to complete. Please respond online by following this link: If you prefer to complete this in hard copy see your local research team member. The survey is open until (date). Your responses will be anonymous and you may withdraw from the study at any point before you submit your completed survey.

Thank you for taking the time to complete this survey.

Sincerely,

The Ethics Needs Assessment Study Research Team

\section{Appendix B: Codebook of Qualitative Responses}

Below are the themes and codes the research team developed to analyze results for question 12 ("What are the three ethical dilemmas/conflicts/issues that you encounter most frequently in your practice?"), the question that yielded the highest number of qualitative responses in our CENAS pilot. These codes and examples are provided to allow for transparency in our data analysis process, and to demonstrate to others who may wish to utilize the CENAS survey how they can use and apply codes. All identifying information has been removed from the illustrative quotes.

Ethical dilemmas most frequently encountered-response themes

End of life

Providing futile or aggressive treatment with poor prognosis (66 responses)

Withdrawal of life sustaining treatment (timing, process, etc.) (54)

Quality of life (52)

Transitioning to palliative care (29)
Illustrative quote (note: some quotes were coded under multiple relevant themes)

"A patient was kept alive on life support with stage 4 lung cancer. None of the physician group would stop futile Rx. because the patient's family was aggressive and threatening lawsuits. The poor patient eventually succumbed but suffered immeasurably and unnecessarily."

"Within one week two patients had the ventilator withdrawn. One patient received proper comfort measures (pain medication, mouth care etc.), the other patient the other did not get anything for pain and comfort. All the staff were very unhappy at the inconsistency in medical orders."

"Once I had to be involved in putting in multiple chest tubes into a patient who had a terminal illness. He had a chronic degenerative neuro disorder. Parents wanted everything done, were not willing to let go. He never showed any response to his environment. It would have helped if the parents were able to be helped to see the benefits of palliation by a palliative care team."

"Female patient with incurable cancer who may have benefitted from palliative treatment to improve symptoms. Husband refused to believe there was a cancer diagnosis, and therefore refused to consider any treatment at all, even for palliation." 
Appendix B continued

Ethical dilemmas most frequently encountered-response themes

Conflict management

Conflict with patient/families (49)

Conflict with MD (between MD, MD and team, MD and family) (31)

Conflict within teams (26)

\section{Professional practice}

Role of surrogate decision maker/Best interest (36)

Moral distress (16)

Confidentiality (re: circle of care) (14)

\section{Communication/team work}

Poor communication within teams (11)

Poor communication with pt./families (43)

Resource issues (beds, staff, time) (26 responses)
Illustrative quote (note: some quotes were coded under multiple relevant themes)
106 responses

“Terminal cancer pt. kept alive in ICU at sister's request, totally unrealistic expectations- health care team did not take into consideration wishes of husband or explore family dynamics - put rest of family through unnecessary pain."

"The patient and family had one opinion and the surgeon another, the rest of the health care team was obliged to go along with the surgeon's plan of care."

"... being frustrated that family and or staff have not be updated re: patient's condition. This causes decisionmaking meeting to be delayed. Staff should be encouraged and supported to voice concern and advocate for patient and family, not reprimanded."

93 responses

"On numerous occasions, patients will express the wish of no further treatment, only to have that decision changed by family members. Very clear guidelines from the outset regarding treatment options would be helpful."

"The nurses in the ICU live with moral dilemmas every day in their practice It demoralizes the nursing group to have to provide care to patients who should be receiving excellent palliative care, not subjected to every invasive treatment known to modern medicine."

“...patient told doctor he didn't want to go back to ICU for ventilation.... A friend of the family (not even the SDM) insisted on the decision being reversed and the medical team complied."

\section{4 responses}

“.....communication would be beneficial to avoid team conflict; ensuring a non-punitive setting for expressing one's own feelings/reactions to a situation; a core provider to allow for consistency with family communications despite other team members rotating on and off."

"A family of a patient who had attempted to overdose were unaware of the issues that brought the patient to the hospital. The major issue in the situation was the poor and abrupt communication from the resident to the family. It could have been avoided if the resident had sat down with the family and explained why the information needed to remain confidential and spoke with the patient and encouraged the patient to be open and honest with family."

"...I was involved with a young gentleman who came into hospital with a severed urethra. What bothered me so much was that the longer the procedure was put off the higher the risk of impotency..." 


\section{Appendix C: Neonatal Intensive Care Unit Ethics Education Plan}

\begin{tabular}{|c|c|c|c|}
\hline Sequence & Topic & Education format & Resources \\
\hline Ongoing & $\begin{array}{l}\text { Case reviews of } \\
\text { ethically } \\
\text { challenging } \\
\text { scenarios and } \\
\text { lessons learned }\end{array}$ & Bi-monthly teaching rounds & $\begin{array}{l}\text { Ethics consultant; ethics } \\
\text { framework }\end{array}$ \\
\hline Ongoing & $\begin{array}{l}\text { Enhance awareness of } \\
\text { ethics resources } \\
\text { available to staff }\end{array}$ & $\begin{array}{l}\text { Unit newsletter } \\
\text { Hall poster boards }\end{array}$ & $\begin{array}{l}\text { Flyers and posters provided by } \\
\text { ethics program advertising } \\
\text { the ethics consultation } \\
\text { service and monthly ethics } \\
\text { grand rounds }\end{array}$ \\
\hline $\begin{array}{l}\text { Introductory } \\
\text { Session }\end{array}$ & $\begin{array}{l}\text { Presentation of local } \\
\text { CENAS results and } \\
\text { draft learning plan }\end{array}$ & $\begin{array}{l}\text { Interprofessional education } \\
\text { rounds }\end{array}$ & $\begin{array}{l}\text { Facilitators: ethicist and ethics } \\
\text { consultant; CENAS } \\
\text { presentation }\end{array}$ \\
\hline Topic 1 & $\begin{array}{l}\text { Introduction to } \\
\text { hospital ethical } \\
\text { decision-making } \\
\text { framework }\end{array}$ & $\begin{array}{l}\text { Interprofessional education } \\
\text { rounds } \\
\text { Apply framework to common } \\
\text { ethical dilemmas in NICU } \\
\text { (i.e., pain management and } \\
\text { symptom control for the } \\
\text { palliative infant) }\end{array}$ & $\begin{array}{l}\text { Facilitators: ethicist and ethics } \\
\text { consultant; standard slide } \\
\text { presentation with NICU case } \\
\text { scenarios }\end{array}$ \\
\hline Topic 2 & $\begin{array}{l}\text { Strategies for working } \\
\text { with challenging } \\
\text { patient/family } \\
\text { situations }\end{array}$ & $\begin{array}{l}\text { Interprofessional education } \\
\text { rounds }\end{array}$ & $\begin{array}{l}\text { Facilitators: social worker and } \\
\text { ethics consultant; standard } \\
\text { slide presentation with } \\
\text { NICU case scenarios }\end{array}$ \\
\hline Topic 3 & $\begin{array}{l}\text { Role of the SDM and } \\
\text { staff in end of life } \\
\text { decision making for } \\
\text { the newborn }\end{array}$ & Pediatric grand rounds & $\begin{array}{l}\text { Panel discussion: ethicist, } \\
\text { ethics consultant, legal } \\
\text { counsel, professional } \\
\text { practice leaders }\end{array}$ \\
\hline Topic 4 & $\begin{array}{l}\text { Dealing with } \\
\text { prognostic } \\
\text { uncertainty and } \\
\text { truth telling }\end{array}$ & $\begin{array}{l}\text { Neonatal/maternal fetal } \\
\text { medicine grand rounds }\end{array}$ & $\begin{array}{l}\text { Facilitators: ethicist, ethics } \\
\text { consultant and medical } \\
\text { director. Case based } \\
\text { scenarios using ethics } \\
\text { framework }\end{array}$ \\
\hline Topic 5 & $\begin{array}{l}\text { Ethics of withholding } \\
\text { and withdrawing } \\
\text { treatments }\end{array}$ & $\begin{array}{l}\text { Interprofessional education } \\
\text { rounds }\end{array}$ & $\begin{array}{l}\text { Panel: social worker, ethics } \\
\text { consultant and medical } \\
\text { director; standard slide } \\
\text { presentation with NICU case } \\
\text { scenarios }\end{array}$ \\
\hline
\end{tabular}

This education plan was developed after a close review of the neonatal unit specific CENAS results. The majority of the respondents from the NICU (61\%), felt that ethics education was very important, however, only $16 \%$ felt that adequate ethics education was provided to staff. Forty-six percent of respondents identified encountering an ethical issue daily or weekly. The top four areas requiring further education were: strategies for working with challenging patient and family situations; ethical issues related to pain, symptom control and sedation; breaking bad news/truth telling; and withholding/withdrawing life sustaining treatments. 
Respondents identified their preferred methods of learning as facilitated informal discussion and interdisciplinary team rounds.

Given this preference for interactive discussions, two types of educational initiatives were planned over a 10 month period. The first involves bi-monthly case reviews. The team identifies a particularly challenging case from the previous month. The local Ethics Consultant reviews the case with various stakeholders to ensure she has a full picture of the issues involved. She facilitates conversations about the case with the interprofessional team during teaching rounds, to help identify relevant values, principles and lessons learned for future cases. The second strategy involves using presentation modules developed by the research team to address particular ethics topics, augmented with local cases and content expertise. These presentations are conducted by the Ethics Consultant or Ethicist, in collaboration with the unit educator at bimonthly interprofessional education rounds or grand rounds.

\section{References}

Frolic, A., Jennings, B., Seidlitz, W., Andreychuk, S., Djuric-Paulin, A., Flaherty, B. \& Peace, D. (2012). From reactive to proactive: Developing a valid clinical ethics needs assessment survey to support ethics program strategic planning (Part 1 of 2). HEC Forum. doi:10.1007/s10730-012-9204-y.

Hart, S. E. (2005). Hospital ethical climates and registered nurses' turnover intentions. Image-The Journal of Nursing Scholarship, 37, 173-177.

McDaniel, C. (1998). Ethical environment: Reports of practicing nurses. Nursing Clinics of North America, 33, 363-372.

Olson, L. (1998). Hospital nurses' perceptions of the ethical climate of their work setting. Image-The Journal of Nursing Scholarship, 30, 345-349.

Olson, L. (2002). Ethical climates as the context for nurse retention. Chart, 99(6), 3-7.

Pauly, B., Varcoe, C., Storch, J., \& Newton, L. (2009). Registered nurses' perceptions of moral distress and ethical climate. Nursing Ethics, 16(5), 561-573.

Pearlman, R. A., Cohen, J. H., Foglia, M. B., \& Fox, E. (2013). Perceptions of clinical ethics practices: IntegratedEthicsTM staff survey data from the VA health care system. AJOB Primary Research, (1), (in press).

Silverman, H. J. (2000). Organizational ethics in healthcare organizations: Proactively managing the ethical climate to ensure organizational integrity. HEC Forum, 12(3), 202-215. 